\title{
TRP14 promotes resistance to cisplatin by inducing autophagy in ovarian cancer
}

\author{
WEN-XI TAN ${ }^{1}$, TIAN-MIN XU ${ }^{1}$, ZI-LONG ZHOU ${ }^{2}$, XUE-JIAO LV ${ }^{3}$, \\ JIAN LIU $^{1}$, WEN-JING ZHANG ${ }^{4}$ and MAN-HUA CUI ${ }^{1}$

\begin{abstract}
${ }^{1}$ Department of Obstetrics and Gynecology, The Second Hospital of Jilin University, Changchun, Jilin 130041;
${ }^{2}$ National Engineering Laboratory for Druggable Gene and Protein Screening, Northeast Normal University, Changchun, Jilin 130024; ${ }^{3}$ Department of Respiratory Medicine, The Second Hospital of Jilin University, Changchun, Jilin 130041;

${ }^{4}$ Department of Clinical Laboratory, The First Affiliated Hospital of Zhengzhou University, Zhengzhou,
\end{abstract} Henan 450052, P.R. China

Received January 29, 2019; Accepted July 3, 2019

DOI: $10.3892 /$ or.2019.7258

\begin{abstract}
Cisplatin is a common chemotherapeutic agent against ovarian cancer; however, drug resistance is a major limiting factor for its use in clinical treatment. The underlying mechanisms of cisplatin resistance in ovarian cancer have not yet been fully elucidated. Thus, this study aimed to elucidate some of the mechanisms responsible for resistance to cisplatin in ovarian cancer. The results demonstrated that the cisplatin-resistant human ovarian cancer cell lines, SKOV3/DDP and A2780/DDP, exhibited higher autophagy levels than the control ovarian cancer cell lines, SKOV3 and A2780. Moreover, autophagy inhibition by 3-methyladenine or shRNA against autophagy-related gene (ATG) 5 potentiated the cytotoxicity induced by cisplatin, whereas autophagy induction by rapamycin (Rapa) increased cell survival. Exposure to cisplatin induced an upregulation in the expression of thioredoxin-related protein of 14 kDa (TRP14). Furthermore, TRP14 knockdown or overexpression decreased or increased the autophagy response and cisplatin resistance, and this effect was reversed by treatment with Rapa or ATG5 knockdown. The findings of this study also suggested that TRP14 induced autophagy and chemoresistance via the 5'AMP-activated protein kinase (AMPK)/mammalian target of rapamycin (mTOR)/p70S6K signaling pathway. Importantly, the data from a tissue array revealed a positive association between TRP14 and Beclin1 in human ovarian cancer and marginal tissues. These findings have identified, for the first time, to the best of our knowledge, that TRP14 induces autophagy and
\end{abstract}

Correspondence to: Professor Man-Hua Cui, Department of Obstetrics and Gynecology, The Second Hospital of Jilin University, 218 Ziqiang Street, Changchun, Jilin 130041, P.R. China

E-mail: cuimanhua@126.com

Key words: thioredoxin-related protein of $14 \mathrm{kDa}$, cisplatin resistance, ovarian cancer, autophagy, 5'AMP-activated protein kinase/mammalian target of rapamycin/p70S6K signaling pathway consequently cisplatin resistance in ovarian cancer cells via the AMPK/mTOR/p70S6K signaling pathway. This in turn renders TRP14 as a potential predictor or target in ovarian cancer therapy.

\section{Introduction}

Ovarian cancer is the most lethal gynecological malignancy and is the fifth leading cause of cancer-related mortality among women in developing countries (1). Patients with ovarian cancer are treated with surgical debunking, followed by chemotherapy with a platinum-based drug or paclitaxel (2). In addition, cisplatin (also known as DDP) is recommended as a common chemotherapeutic agent. As patients eventually become resistant to cytotoxic agents, the overall five-year survival rate is only $44 \%$ (3-5). Thus, chemoresistance is one of the main causes limiting the effectiveness of chemotherapy (6).

There is an increasing evidence regarding the association of autophagy and chemoresistance (7). Autophagy is often known as type II programmed cell death, and is an evolutionarily conserved catabolic process that is responsible for the degradation and recycling of long-lived or aggregated proteins, and excess or defective organelles. Autophagy is induced by a group of autophagy-related (ATG) genes and activates the conversion of cytosolic microtubule-associated protein light chain $3 \mathrm{~A}$ (LC3A) into LC3B $(8,9)$. Autophagy is generally low under basal conditions, while altered autophagic activity has been observed under stress conditions, such as starvation (10), diverse diseases (11), irradiation $(12,13)$ and chemotherapy (14). Although several studies have demonstrated that various anti-tumor agents induce autophagic cell death in cancer cells (15-17), there is compelling evidence to indicate that autophagy contributes to chemoresistance in various types of cancer $(18,19)$. It has recently been reported that miR-181a suppresses autophagy and sensitizes gastric cancer cells to cisplatin (20) and also that the suppression of autophagy enhances the efficacy of sunitinib in clear cell ovarian carcinoma (21). Autophagy has also been shown to contribute to taxol resistance in human colorectal cancer cells (22). 
Thioredoxin-related protein of $14 \mathrm{kDa}$ (TRP14) is a novel disulfide reductase that belongs to the thioredoxin (TXN) family and was discovered in 2004 (23). It is also known as thioredoxin domain containing 17 (TXNDC17) and thioredoxin-like 5 (TXNL5) (24). TRP14 is a TrxR1-dependent reductase that can effectively reduce both $S$-nitrosothiol and L-cystine levels. The biological function of TRP14 remains unclear however. Previous studies have demonstrated the role of TRP14 in autophagy in mediating taxol resistance by stimulating autophagy in colorectal and ovarian cancer cells $(22,25)$. Thus, we hypothesized that there may be an association among TRP14, autophagy and cisplatin resistance in ovarian cancer.

Although there is increasing interest in the modulation of autophagy for cancer therapy, the role of TRP14 in autophagy and cisplatin resistance in ovarian cancer cell lines remains unknown, at least to the best of our knowledge. Hence, in this study, we evaluated the level and effect of autophagy and the function of TRP14 in cisplatin-resistant ovarian cancer cell lines. The findings of this study demonstrate that TRP14 plays a key role in cisplatin resistance through the induction of autophagy. Thus, TRP14 may prove to be a potential predictor or target in ovarian cancer therapy.

\section{Materials and methods}

Cell lines, reagents and antibodies. The human ovarian cancer cell lines, A2780 and SKOV3, were obtained from the European Collection of Authenticated Cell Cultures (93112519, ECACC) and the American Type Culture Collection (HTB-77, ATCC), respectively and maintained in RPMI-1640 (10-040-CVR, Corning, Inc.) and McCoy 5A medium (16600-108, Gibco; Thermo Fisher Scientific) supplemented with $10 \%$ fetal bovine serum (FBS) at $37^{\circ} \mathrm{C}$ in $5 \% \mathrm{CO}_{2}$. The cisplatin-resistant cells, SKOV3/DDP and A2780/DDP, were established by exposing the cells to gradually increasing concentrations (from 0 to $25 \mu \mathrm{g} / \mathrm{ml}$ ) of cisplatin for 6 months (data not shown). Cisplatin was purchased from Hansoh Pharmaceutical Co., Ltd. 3-Methyladenine (3-MA), rapamycin (Rapa), compound $\mathrm{C}$ and monodansylcadaverine (MDC) were purchased from Sigma-Aldrich. The primary antibody to TRP14 (ab121725/dilution, 1:500) was purchased from Abcam. The primary antibodies for ATG5 (\#12994/dilution, 1:1,000), Beclin1 (\#3495/dilution, 1:1,000), LC3B (\#3868/dilution, 1:1,000), p-5' AMP-activated protein kinase (AMPK; \#2537/dilution, 1:1,000), p-mammalian target of rapamycin (mTOR; \#5536/dilution, 1:1,000), p-p70S6K (\#9204/dilution, 1:1,000), AMPK (\#5832/dilution, 1:1,000), mTOR (\#2983/dilution, 1:1,000) and p70S6K (\#2708 /dilution, 1:1,000) were obtained from Cell Signaling Technology Inc. The antibody for GAPDH (sc-47724) was purchased from Santa Cruz Biotechnology.

Cell viability assay. Cells were plated in triplicate in 96-well plates overnight and then were treated with or without $200 \mathrm{nM}$ Rapa for $24 \mathrm{~h}$ or treated with $4 \mu \mathrm{M}$ compound $\mathrm{C}$ for $12 \mathrm{~h}$. After $12 \mathrm{~h}$, the cells were treated with various concentrations of cisplatin (from 0 to $16 \mu \mathrm{g} / \mathrm{ml}$ ) for $24 \mathrm{~h}$. Cell viability was measured using a Cell Counting kit-8 (CCK-8, Dojindo Molecular Technologies, Inc.) assay according to the manufacturer's instructions (25). Cell viability was calculated according to the following equation: Cell viability $=\mathrm{OD}$ value of experimental group/OD value of control group x $100 \%$.

Western blot analysis. Cells were harvested and washed with phosphate-buffered saline (PBS). The proteins were extracted, and western blot analysis was performed as previously described (26). Briefly, the cells were dissolved (for $30 \mathrm{~min}$ ) in lysis buffer containing 1\% PMSF in RIPA buffer (Thermo Fisher Scientific) and quantified using the BCA Protein Assay (Thermo Fisher Scientific). Proteins $(30 \mu \mathrm{g})$ were resolved on $12 \%$ SDS-PAGE, transferred onto polyvinylidenedifluoride transfer membranes (PVDF) and blocked with 5\% non-fat dry milk in TBST for $1 \mathrm{~h}$ at room temperature. The membranes were incubated with the indicated antibodies overnight at $4{ }^{\circ} \mathrm{C}$, followed by the incubation with the corresponding secondary antibodies (anti-rabbit \#7074 and anti-mouse \#7076/dilution, 1:5,000, Cell Signaling Technology Inc.) conjugated with horseradish peroxidase-conjugated (HRP) for $1 \mathrm{~h}$ at room temperature. The bands were detected with an EZ-ECL kit (BI Biological Industries, 20-500-120) in the MicroChemi bio-imaging system (DNR). ImageJ was used for densitometry (Image J 1.46r, National Institutes of Health).

Plasmids and shRNA transfection. The pcDNA3.1(C)-TRP14 plasmid was constructed based on the following description. The fragment (182 to 553) of TRP14 mRNA was synthesized and inserted into the pcDNA3.1(C) vector (Invitrogen; Thermo Fisher Scientific, \#V790-20). The pcDNA3.1(C) vector was considered as the mock control. DNA oligonucleotides carrying shRNA (Invitrogen-Life Technology; Thermo Fisher Scientific) were constructed into the pLKO.1 plasmid (Addgene Plasmid \#8453). The packaging plasmid psPAX2 (Addgene Plasmid \#12260) and envelop plasmid pMD2.G (Addgene Plasmid \#12259) were transfected into 293T cells (from Cell Bank of the Chinese Academy of Sciences)with recombinant plasmids using LipofectamineTM2000 (Invitrogen; Thermo Fisher Scientific). The supernatant containing lentiviruses was collected after $36 \mathrm{~h}$. The sequences of the shRNAs were as follows, TRP14 shRNA\#1, GTGCCTACACTACTTAAGT; TRP14 shRNA\#2, ACCTAACCTCACCACTGAA; ATG5 shRNA\#1, GCTACTCTGGATGGGATTG; ATG5 shRNA\#2, ATTGGCTCAATTCCATGAA; and control shRNA, CAC ACCGTTTCGTGGCTTT. Cells were grown till $80 \%$ confluence prior to transfection. Transfected cells were grown for 2 weeks in the presence of puromycin $(0.2 \mu \mathrm{g} / \mathrm{ml})$ before they were used for subsequent experimentation.

MDC staining assay. Following treatment with $200 \mathrm{nM}$ Rapa for $12 \mathrm{~h}$, the cells were washed twice with PBS and incubated with $50 \mathrm{mM} \mathrm{MDC}$ at $37^{\circ} \mathrm{C}$ for $1 \mathrm{~h}$. The cells were washed with PBS and then fixed with $4 \%$ paraformaldehyde (PFA) solution for $15 \mathrm{~min}$. Finally, the cells were analyzed under an Olympus BX50 fluorescence microscope (Olympus).

RFP-LC3 analysis. The cells were then transfected with a GFP-RFP-LC3 plasmid (Addgene Plasmid \#84573) using LipofectamineTM2000 and 24 h later, the cells were transferred onto coverslips. The cells were washed with PBS and fixed with $4 \%$ PFA in PBS for $30 \mathrm{~min}$ at room temperature. The fixed cells were washed twice with PBS and then 


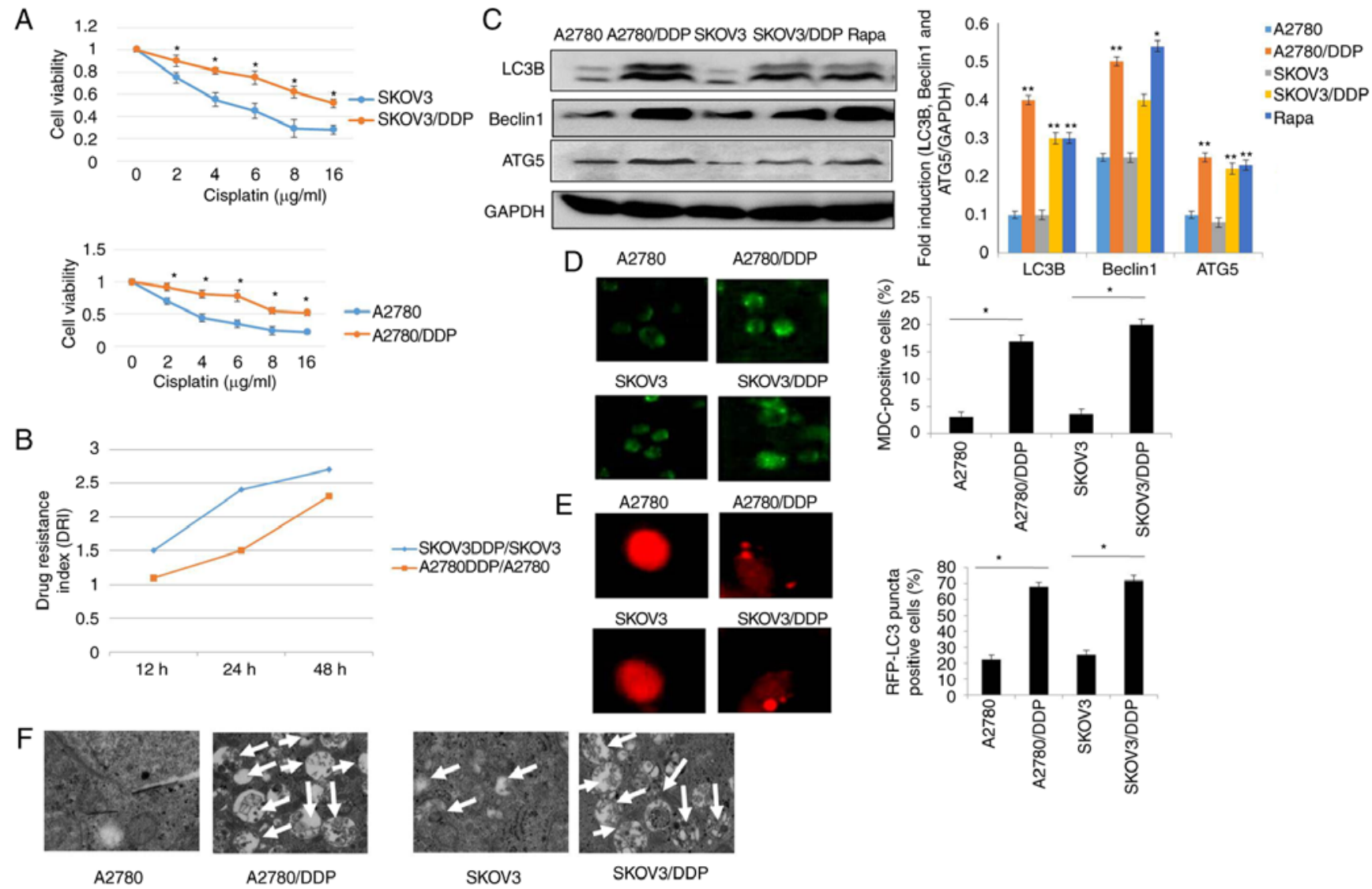

Figure 1. Autophagy is induced in cisplatin-resistant human ovarian cancer cell lines. (A) A2780, A2780/DDP, SKOV3 and SKOV3/DDP cells were incubated with the indicated concentrations of cisplatin for $24 \mathrm{~h}$, and cell viability was then measured by CCK-8 assay. Values were presented as the mean \pm SEM $(\mathrm{n}=3) .{ }^{*} \mathrm{P}<0.05$, statistical significance vs. normal A2780 and SKOV3 cells. (B) Drug resistance index (DRI) of cisplatin in A2780, A2780/DDP, SKOV3 and SKOV3/DDP cells. (C) The levels of LC3, Beclin1 and ATG5 were detected by western blot analysis in A2780, A2780/DDP, SKOV3 and SKOV3/DDP cells. Rapamycin (Rapa) was used as a positive control. GAPDH served as a loading control. Results were repeated in independent experiments. ${ }^{*}<0.05$ and ${ }^{* *} \mathrm{P}<0.01$, statistical significance vs. normal A2780 and SKOV3 cells. (D) MDC staining of A2780, A2780/DDP, SKOV3 and SKOV3/DDP cells. "P<0.05, statistical significance vs. normal A2780 and SKOV3 cells. (E) A2780, A2780/DDP, SKOV3 and SKOV3/DDP cells were transfected with GFP-RFP-LC3-plasmid. After $24 \mathrm{~h}$, representative images of GFP- RFP-LC3-II-positive puncta were photographed by using a confocal fluorescence microscope. ${ }^{*} \mathrm{P}<0.05$, statistical significance vs. normal A2780 and SKOV3 cells. (F) The ultrastructural changes of A2780, A2780/DDP, SKOV3 and SKOV3/DDP cells as measured by transmission electron microscopy are shown. The white arrows indicate the typical images of autophagosomes and autolysosomes.

permeabilized with $0.5 \%$ Triton X-100 in PBS for 2 min on ice. Images were obtained under an Olympus BX50 fluorescence microscope (Olympus).

Electron microscopy analysis. Following treatment with $200 \mathrm{nM}$ Rapa for $12 \mathrm{~h}$, and the knockdown or overexpression of TRP14, the cells were harvested and washed with PBS. The samples were processed and detected as previously described (27). Briefly, the cells were exposed to $10 \mathrm{nM}$ paclitaxel for $24 \mathrm{~h}$ and fixed with $2.5 \%$ glutaraldehyde solution (Sigma-Aldrich, G5882) overnight, then post-fixed with $1 \%$ OsO4 and dehydrated standard in graded ethanol, embedded in 812 resin (Ted Pella, 18109). Thin sections were sliced and stained with $2 \%$ uranyl acetate, and then examined with a JEM-100CX transmission electron microscope (Jeol).

Drug resistance index (DRI) assay. Four groups of cells (SKOV3DDP/SKOV3 and A2780DDP/A2780) were obtained for the preparation of cell suspension. Cell concentration was adjusted to $5 \times 10^{5} / \mathrm{ml}$ and $200 \mu \mathrm{l}$ was placed in each well of a 96 -well culture plate. Following a $24 \mathrm{~h}$ culture, various concentrations (from 0 to $25 \mu \mathrm{g} / \mathrm{ml}$ ) of cisplatin were added.
A control group without drugs was also set. All cells were cultured at $37^{\circ} \mathrm{C}$ and $5 \% \mathrm{CO}_{2}$ for $24 \mathrm{~h}$. Subsequenlty, $20 \mu \mathrm{l}$ of MTT $(5 \mathrm{mg} / \mathrm{ml})$ solution were added to each well and the cells were cultured for an additional $4 \mathrm{~h}$. Supernatants were discarded after termination of the culture and $150 \mu \mathrm{l}$ of dimethyl sulphoxide (DMSO) were added to each well. The plates were shaken for $10 \mathrm{~min}$ and a microplate reader was used to measure the optical density (OD) value at a wavelength of $570 \mathrm{~nm}$ to calculate cell survival rate. The following equation was used to calculate the cell survival rate: Cell survival rate $=($ the OD value in each experiment well/the OD value in the control well) $\times 100 \%$. The $50 \%$ of inhibition concentration (IC50) of drug was measured by chartography. The drug resistance index (DRI)=the IC50 of drug-resistant cells/the IC50 of parent cell line. MTT experiments were repeated 3 times on time points(every $24 \mathrm{~h}$ ).

Immunohistochemistry. The clinical ovarian cancer and marginal tissue microarray (BC11115b from US Biomax) was analyzed based on the following description. After dewaxing and hydration, the tissue microarray slides were boiled in sodium citrate buffer for 10 min for antigen recovery, and 

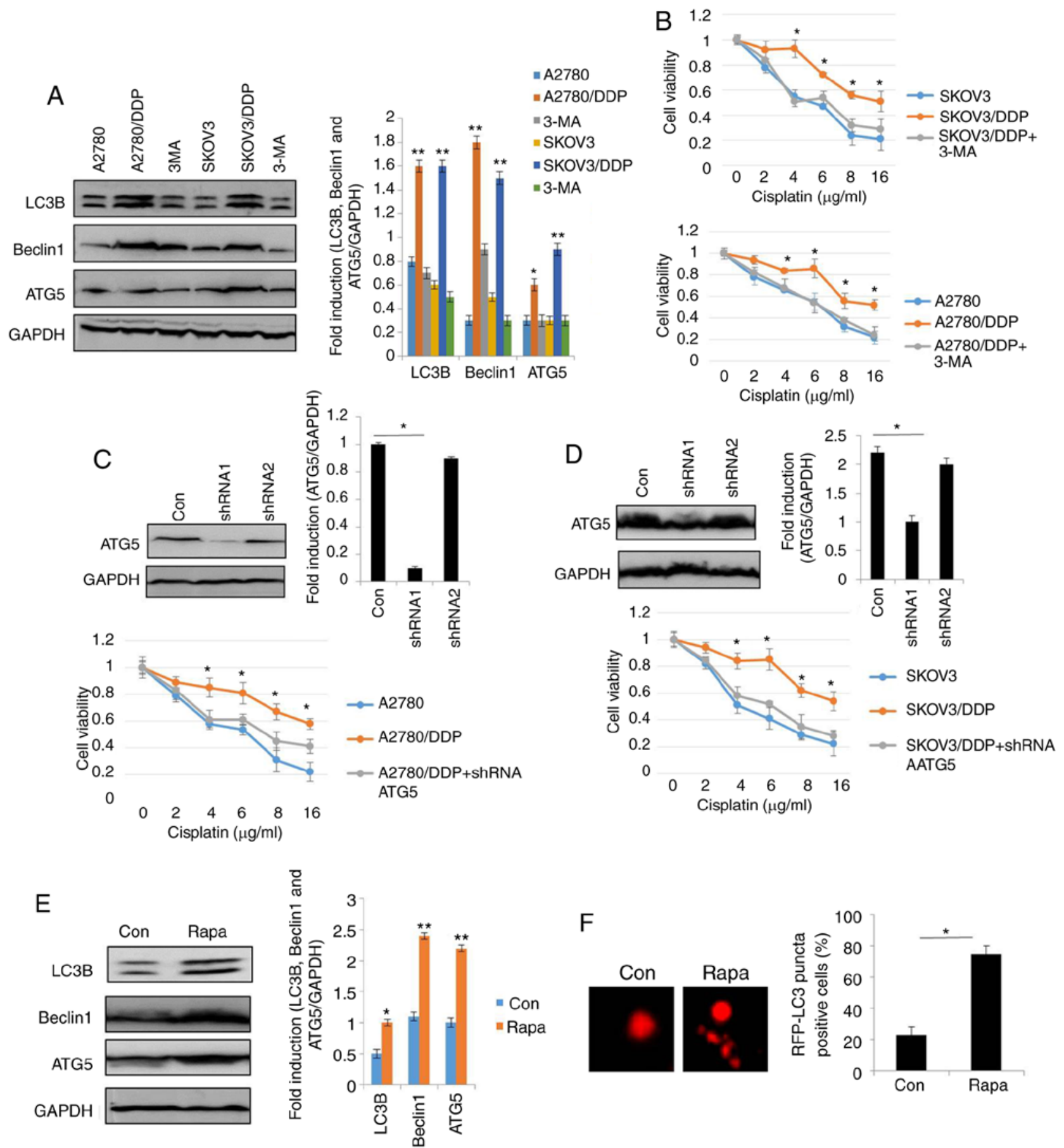

Figure 2. Autophagy regulates cisplatin resistance in human ovarian cancer cells. (A) The levels of LC3, Beclin1 and ATG5 were detected by western blot analysis in SKOV3/DDP and A2780/DDP cells treated with $5 \mathrm{nM} 3-\mathrm{MA}$ for $24 \mathrm{~h}$. GAPDH was used as an internal control. Results were repeated in independent experiments. ${ }^{*} \mathrm{P}<0.05$ and ${ }^{* *} \mathrm{P}<0.01$, statistical significance vs. 3-MA-treated A2780 and SKOV3 cells. (B) The effect of the autophagy inhibitor, 3-MA, on the viability of SKOV3/DDP and A2780/DDP cells was tested. Cell viability was measured by CCK-8 assay. The Kruskal-Wallis was used for multiple comparisons and then Mann Whitney $\mathrm{U}$ test and Bonferroni's correction were applied. The values were presented as the means $\pm \mathrm{SEM}(\mathrm{n}=3)$. ${ }^{*} \mathrm{P}<0.05$, statistical significance vs. 3-MA-treated cells. (C) Abrogation of ATG5 potentiates cisplatin cytotoxicity in SKOV3/DDP cells. The Kruskal-Wallis was used for multiple comparisons and then Mann Whitney U test and Bonferroni's correction were applied. The values were presented as the means \pm SEM $(n=3)$. "P<0.05, statistical significance vs. ATG5-knockdown cells. (D) Abrogation of ATG5 potentiates cisplatin cytotoxicity in A2780/DDP cells. The Kruskal-Wallis was used for multiple comparisons and then Mann Whitney $\mathrm{U}$ test and Bonferroni's correction were applied. The values were presented as the means \pm SEM $(n=3)$. ${ }^{\prime} \mathrm{P}<0.05$, statistical significance vs. ATG5-knockdown cells. (E) The levels of LC3, Beclin1 and ATG5 were detected by western blot analysis in SKOV3 cells treated with $200 \mathrm{nM}$ Rapa for $12 \mathrm{~h}$. ${ }^{*} \mathrm{P}<0.05$ and ${ }^{* *} \mathrm{P}<0.01$, statistical significance vs. control. (F) SKOV3 cells were transfected with GFP-RFP-LC3-plasmid overnight. Following $12 \mathrm{~h}$ of exposure to $200 \mathrm{nM}$ Rapa, representative images of GFP- RFP-LC3-II-positive puncta were obtained using a confocal fluorescence microscope. " $\mathrm{P}<0.05$, statistical significance vs. control SKOV3 cells.

immersed in $3 \% \mathrm{H}_{2} \mathrm{O}_{2}$ for 10 min to quench endogenous peroxidase. After being blocked with 5\% horse serum for $35 \mathrm{~min}$, the slides were incubated with primary antibodies against TRP14 (dilution, 1:200; ab121725, Abcam); or Beclin1 (dilution, 1:200; ab62557, Abcam) at $4^{\circ} \mathrm{C}$ overnight. Subsequently, the sections were rinsed and then coated with HRP-conjugated secondary 

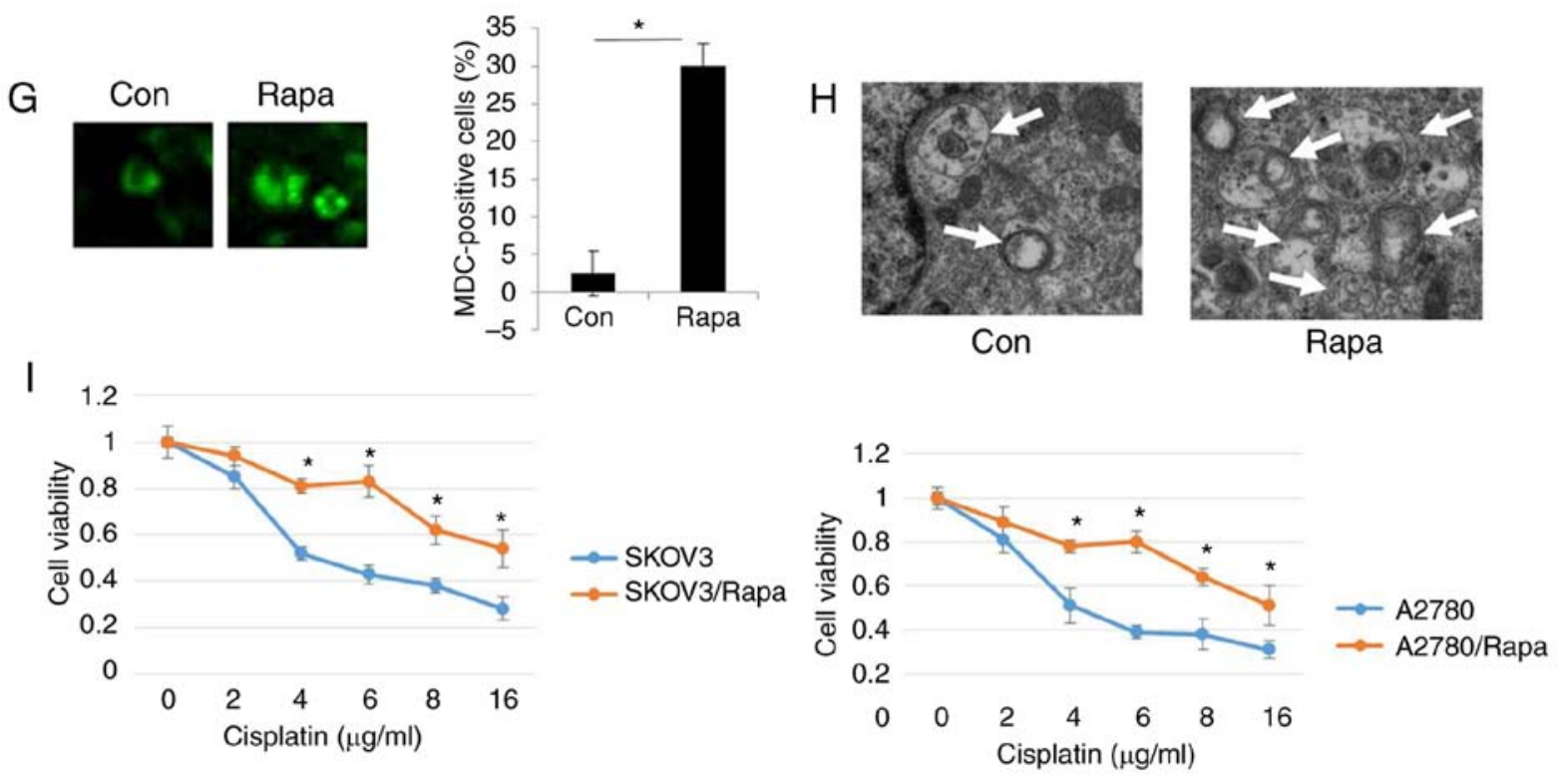

Figure 2. Continued. Autophagy regulates cisplatin resistance in human ovarian cancer cells. (G) MDC staining of SKOV3 cells following treatment with $200 \mathrm{nM}$ Rapa for $12 \mathrm{~h}$. ${ }^{*} \mathrm{P}<0.05$, statistical significance vs. control SKOV3 cells. (H) Autophagosome and autolysosome vesicles of SKOV3 cells treated with $200 \mathrm{nM}$ Rapa for $12 \mathrm{~h}$ were visualized by transmission electron microscopy. The white arrows indicate the typical images of autophagosomes and autolysosomes. (I) Effect of the autophagy activator, rapamycin (Rapa) on the viability of SKOV3 cells and A2780 cells was examined. Values were presented as the means \pm SEM $(n=3)$. ${ }^{*}<<0.05$, statistical significance vs. control SKOV3 and A2780 cells.

antibody (dilution, 1:200; ab205718, Abcam) and incubated at $37^{\circ} \mathrm{C}$ for $1 \mathrm{~h}$. DAB (ab64261, Abcam) was used to visualize the immunoreactive sites.

Statistical analysis. All analyses were repeated at least 3 times. Data are expressed as means \pm SD. Statistical analysis of the data was performed using a Student's t-test and two-tailed distribution. The Kruskal-Wallis test was used for multiple comparisons and then Mann Whitney U test as well as Bonferroni's correction were applied as post hoc tests to determine the cell viability difference among the different groups.

\section{Results}

Autophagy is induced in cisplatin-resistant human ovarian cancer cell lines. To identify the chemoresistance of cisplatin-resistant human ovarian cancer cell lines, the cisplatin-resistant human ovarian cancer cell lines, SKOV3/DDP, A2780/DDP, and the control cell lines, SKOV3/A2780, were treated with various concentrations of cisplatin for $24 \mathrm{~h}$. CCK-8 and drug resistance index (DRI) assay were then performed to measure the cell viability and drug sensitivity in the different cells (Fig. 1A and B). The results revealed that the survival of both the SKOV3 and SKOV3/DDP cells decreased in a dose-dependent manner. However, the SKOV3/DDP cells were more resistant to cisplatin, as compared with the SKOV3 cells $(\mathrm{P}<0.05)$. Similar results were clearly observed in the A2780 and A2780/DDP cells (Fig. 1A). Moreover, our data suggested that the DRI was much higher in the SKOV3/DDP compared to A2780/DDP cells, indicating that the SKOV3/DDP cells were more resistant than the A2780/DDP cells. Recently, it has been demonstrated that autophagy is associated with drug resistance (25). Thus, the contribution of autophagy to cisplatin resistance was determined in this study. As shown in Fig 1C, the levels of LC3, Beclin1 and ATG5, which are the characteristics of autophagy $(15,28)$, were elevated in the SKOV3/DDP and A2780/DDP cells when compared with the SKOV3 and A2780 cells, respectively (Rapa treatment was used as a positive control). Furthermore, the acidic vesicular organelles (AVOs) were examined by MDC staining. A greater number of the SKOV3/DDP and A2780/DDP cells were MDC-positive cells compared with their sensitive counterparts, the SKOV3 and A2780 cells (Fig. 1D). According to these observations, the numbers of GFP-RFP-LC3-positive puncta were significantly increased in the cisplatin-resistant ovarian cancer cells (Fig. 1E). More importantly, these results were validated using transmission electron microscopy (Fig. 1F). These data clearly indicated that cisplatin-resistant human ovarian cancer cell lines displayed an enhanced autophagy status when compared with the control cell lines, SKOV3 and A2780.

Autophagy is required for cisplatin resistance in human ovarian cancer cells. To elucidate the role of autophagy in the resistance of human ovarian cancer cell lines to cisplatin, the autophagy inhibitor, 3-MA was used (29). As shown in Fig. 2A, the levels of LC3, Beclin1 and ATG5 were significantly decreased in the SKOV3/DDP and A2780/DDP cells following treatment with $5 \mathrm{nM} 3-\mathrm{MA}$ for $24 \mathrm{~h}$. As expected, treatment with 3-MA significantly decreased the viability of the SKOV3/DDP and A2780/DDP cells (Fig. 2B). To assess the role of autophagy in cisplatin resistance, autophagy was inhibited through genetic methods (silencing of ATG5) in the SKOV3/DDP and A2780/DDP cells. Following the silencing of ATG5, the viability of the SKOV3/DDP and A2780/DDP cells exhibited a significant attenuation (Fig. 2C and D), indicating that the cytotoxic effects of cisplatin were enhanced by ATG5 knockdown. Since the DRI was greater in the SKOV3 

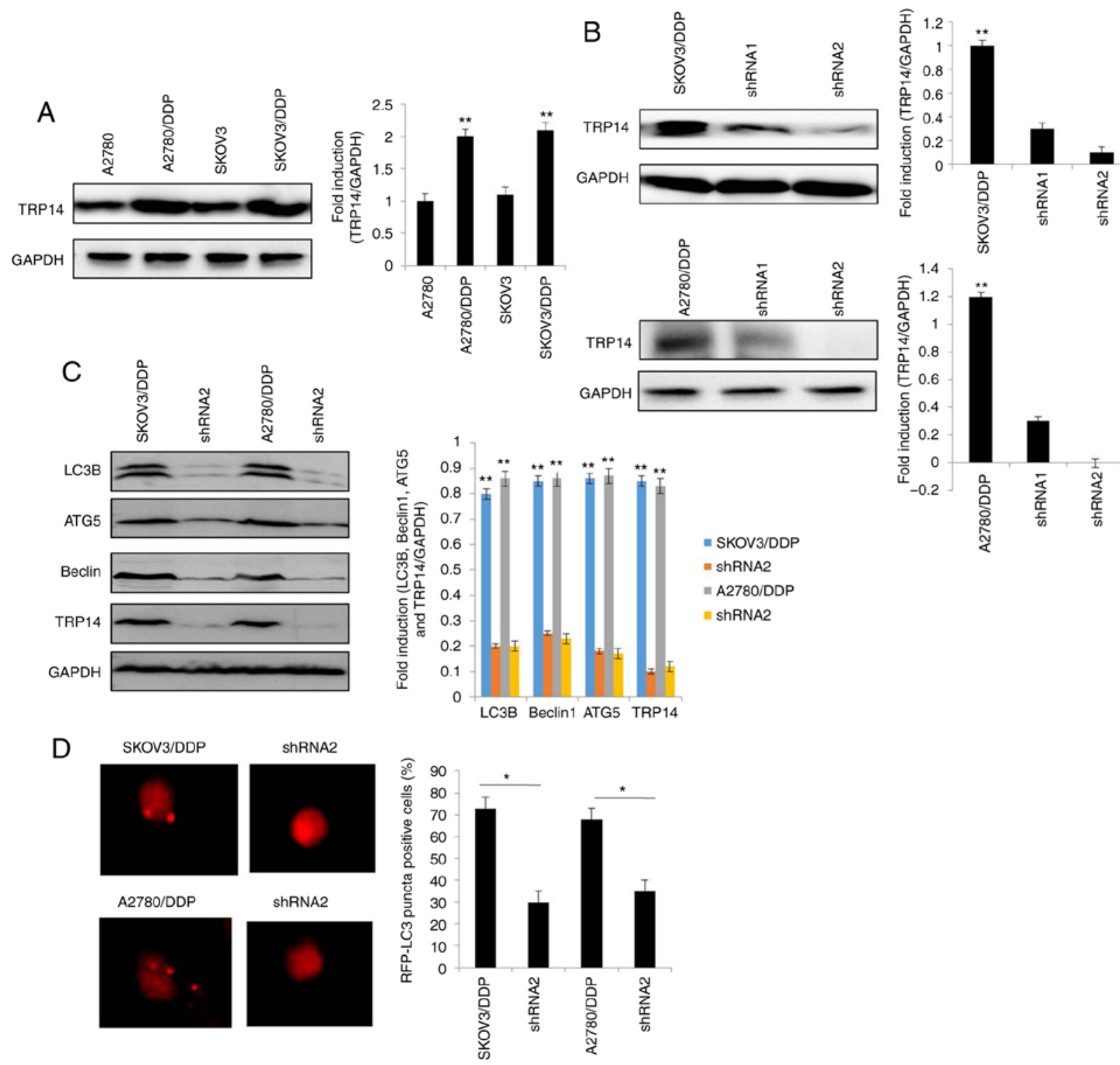

$\mathrm{E}$
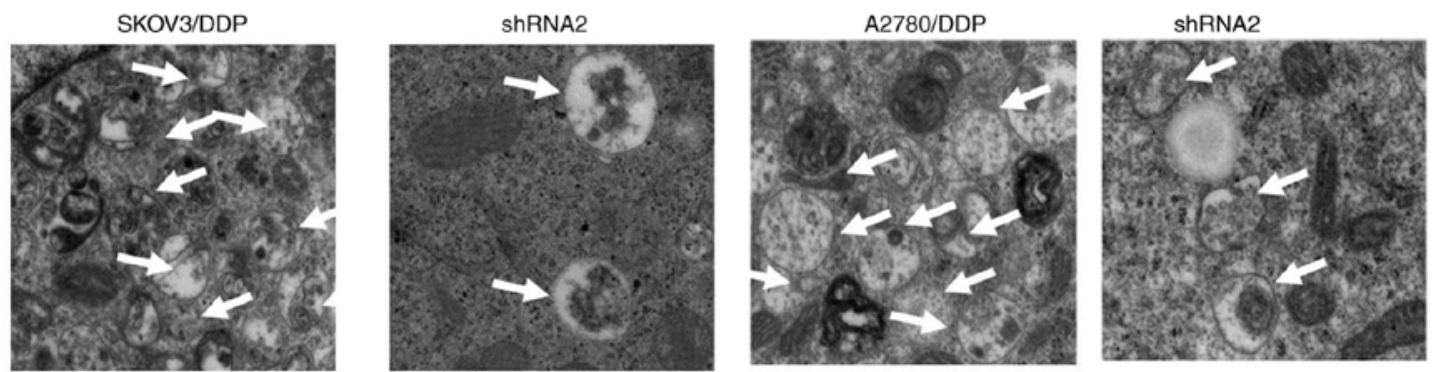

Figure 3. TRP14 knockdown suppresses autophagy-induced cisplatin resistance in SKOV3/DDP and A2780/DDP cells. (A) The levels of TRP14 were detected by western blot analysis in A2780, A2780/DDP, SKOV3 and SKOV3/DDP cells. ${ }^{* *} \mathrm{P}<0.01$ indicates statistical significance vs. normal A2780 and SKOV3 cells. (B) A2780/DDP and SKOV3/DDP cells were transfected with TRP14 shRNA. ${ }^{* *} \mathrm{P}<0.01$ indicates statistical significance vs. TRP14-knockdown cells. (C) Autophagy-associated genes (LC3, Beclin 1 and ATG5) were examined in cells in which TRP14 was knocked down cells by western blot analysis. ${ }^{* *} \mathrm{P}<0.01$ indicates statistical significance vs. TRP14-knockdown cells. (D) Knockdown of TRP14 with shRNA2 in SKOV3/DDP and A2780/DDP cells. The cells were then transfected with GFP-RFP-LC3-plasmid for overnight. Representative images of GFP-RFP-LC3-II-positive puncta were obtained using a confocal fluorescence microscope. "P<0.05, statistical significance vs. TRP14-knockdown cells. (E) Autophagosome and autolysosome vesicles of A2780/DDP and SKOV3/DDP cells were visualized by transmission electron microscopy following transfection with TRP14 shRNA. The white arrows indicate the typical images of autophagosomes and autolysosomes.

cells than in the A2780 cells (Fig. 1B), Rapa (200 nM) was used to induce autophagy in the SKOV3 cells (Fig. 2E-H). The results revealed that the expression levels of LC3, Beclin1 and ATG were markedly upregulated by Rapa in the SKOV3 cells (Fig. 2E). Consistent with the above-mentioned results, MDC staining, GFP-RFP-LC3 transfection and transmission 

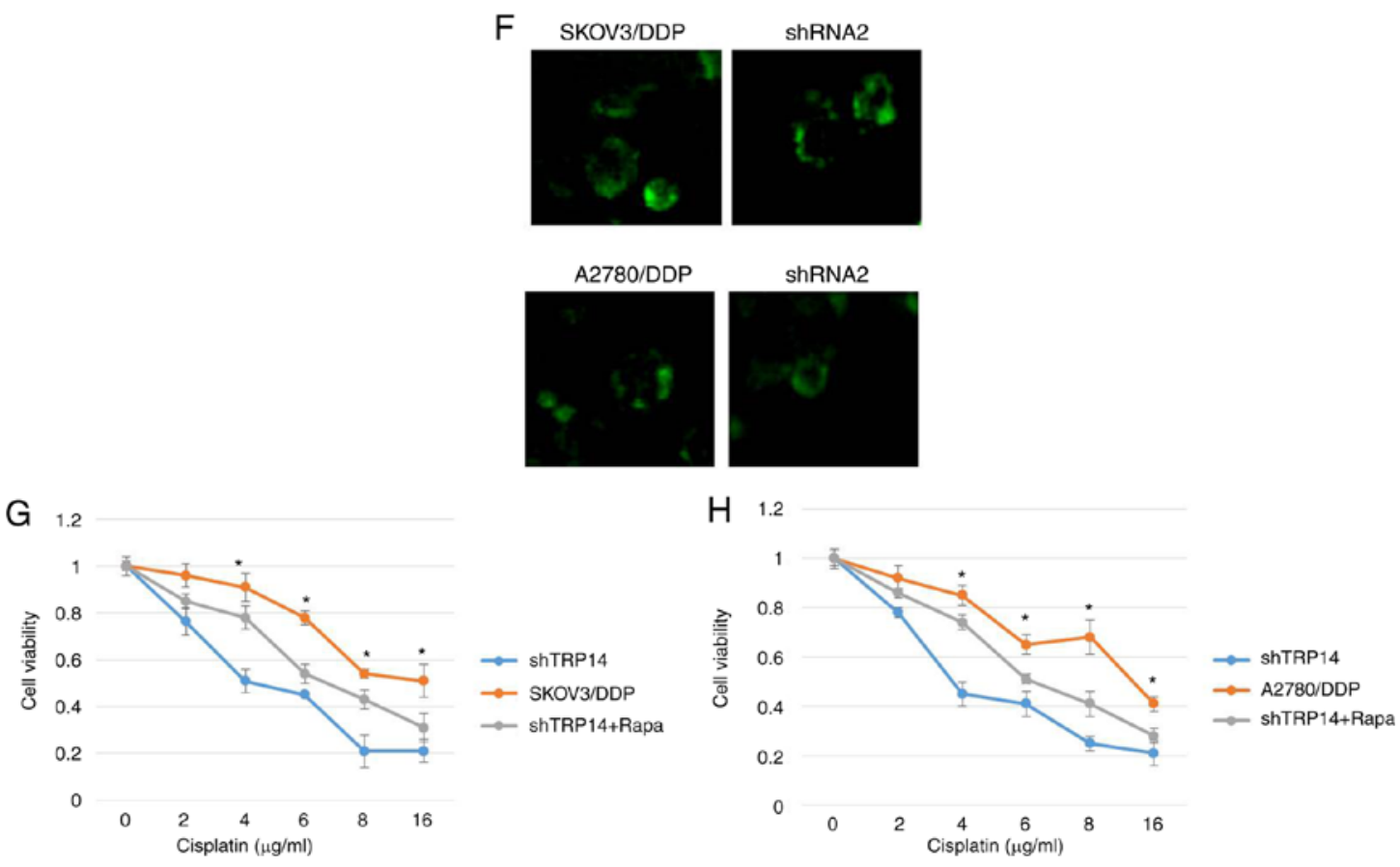

Figure 3. Continued. TRP14 knockdown suppresses autophagy-induced cisplatin resistance in SKOV3/DDP and A2780/DDP cells. (F) MDC staining of A2780/DDP and SKOV3/DDP cells following the knockdown of TRP14. (G) SKOV3/DDP cells were transfected with TRP14 shRNA2. The cells were then treated with or without $200 \mathrm{nM}$ rapamycin (Rapa) for $24 \mathrm{~h}$. After $24 \mathrm{~h}$, the cells were treated with the indicated concentrations of cisplatin (from o to $16 \mu \mathrm{g} / \mathrm{ml}$ ) for $24 \mathrm{~h}$ and cell viability was measured by CCK-8 assay. The Kruskal-Wallis was used for multiple comparisons and then Mann Whitney U test and Bonferroni's correction were applied. The values are presented as the means \pm SEM $(n=3)$. ${ }^{*} \mathrm{P}<0.05$, statistical significance vs. TRP14-knockdown cells. (H) A2780/DDP cells were transfected with TRP14 shRNA2 overnight. The cells were then treated with or without $200 \mathrm{nM}$ Rapa for $24 \mathrm{~h}$. After $24 \mathrm{~h}$, the cells were treated with the indicated concentrations of cisplatin (from 0 to $16 \mu \mathrm{g} / \mathrm{ml}$ ) for $24 \mathrm{~h}$ and cell viability was measured by CCK-8 assay. The Kruskal-Wallis was used for multiple comparisons and then Mann Whitney $\mathrm{U}$ test and Bonferroni's correction were applied. The values are presented as the means \pm SEM $(\mathrm{n}=3) .{ }^{*} \mathrm{P}<0.05$, statistical significance vs. TRP14-knockdown cells.

electron microscopy analysis confirmed that cisplatin triggered autophagy in the SKOV3 cells (Fig. 2F-H), as evidence by the increased number of GFP-RFP-LC3-positive puncta, MDC-positive cells, and autolysosome vesicles. Moreover, cisplatin exhibited significant cytotoxicity in the SKOV3 cells and A2780 cells in a dose-dependent manner (Fig. 2I). These findings suggested that cisplatin induced autophagic cell death in the SKOV3 cells. Similar results were observed in the A2780 cells (data not shown). Taken together, these results clearly demonstrated that autophagy modulated cisplatin resistance in human ovarian cancer cells.

TRP14 knockdown suppresses autophagy-induced cisplatin resistance. Previous studies have reported that TRP14 promotes taxol resistance by inducing autophagy $(22,25)$. Thus, we hypothesized that TRP14 may also participate in autophagy-induced cisplatin resistance in human ovarian cancer cells. The results revealed that the protein expression of TRP14 was significantly increased in the SKOV3/DDP and A2780/DDP cells when compared with the SKOV3 and A2780 cells, respectively (Fig. 3A). To confirm the function of TRP14 in autophagy-regulated cisplatin resistance, TRP14 was knocked down using shRNA against different regions of TRP14 mRNA in the SKOV3/DDP and A2780/DDP cells (Fig. 3B). As shown in Fig. 3C-F, TRP14 knockdown significantly inhibited autophagy in the SKOV3/DDP and A2780/DDP cells, as determined by western blot analysis, MDC staining, transmission electron microscopy observation and GFP-RFP-LC3 transfection. In addition, TRP14 knockdown significantly increased the sensitivity of the SKOV3/DDP and A2780/DDP cells to cisplatin (Fig. 3G and $\mathrm{H})$. To verify the role of autophagy in cisplatin resistance induced by TRP14 knockdown, Rapa was used. As shown in Fig. 3G and H, Rapa promoted resistance to cisplatin when TRP14 was knocked down. Taken together, these data clearly indicated that TRP14 knockdown suppressed autophagy-induced cisplatin resistance in the SKOV3/DDP and A2780/DDP cells.

TRP14 overexpression promotes autophagy and cisplatin resistance in human ovarian cancer cells. To further confirm the role of TRP14, autophagy and cisplatin resistance in human ovarian cancer cells, TRP14 was overexpressed in the SKOV3 and A2780 cells (Fig. 4A). The results revealed that the levels of the autophagy marker proteins, the number of RFP-positive cells and the number of autophagosomes were significantly increased by TRP14 overexpression (Fig. 4B-D). These findings indicated that TRP14 induced autophagy in human ovarian cancer cells. Moreover, TRP14 overexpression exerted protective effects on the ovarian cancer cells against cisplatin (Fig. 4E and F). However, cytoprotection due to TRP14 overexpression was partly reversed by ATG5 knockdown (Fig. 4E and F). Taken together, these results suggested that TRP14 activated autophagy and induced cisplatin resistance, at least partially through the participation of ATG5. 
A
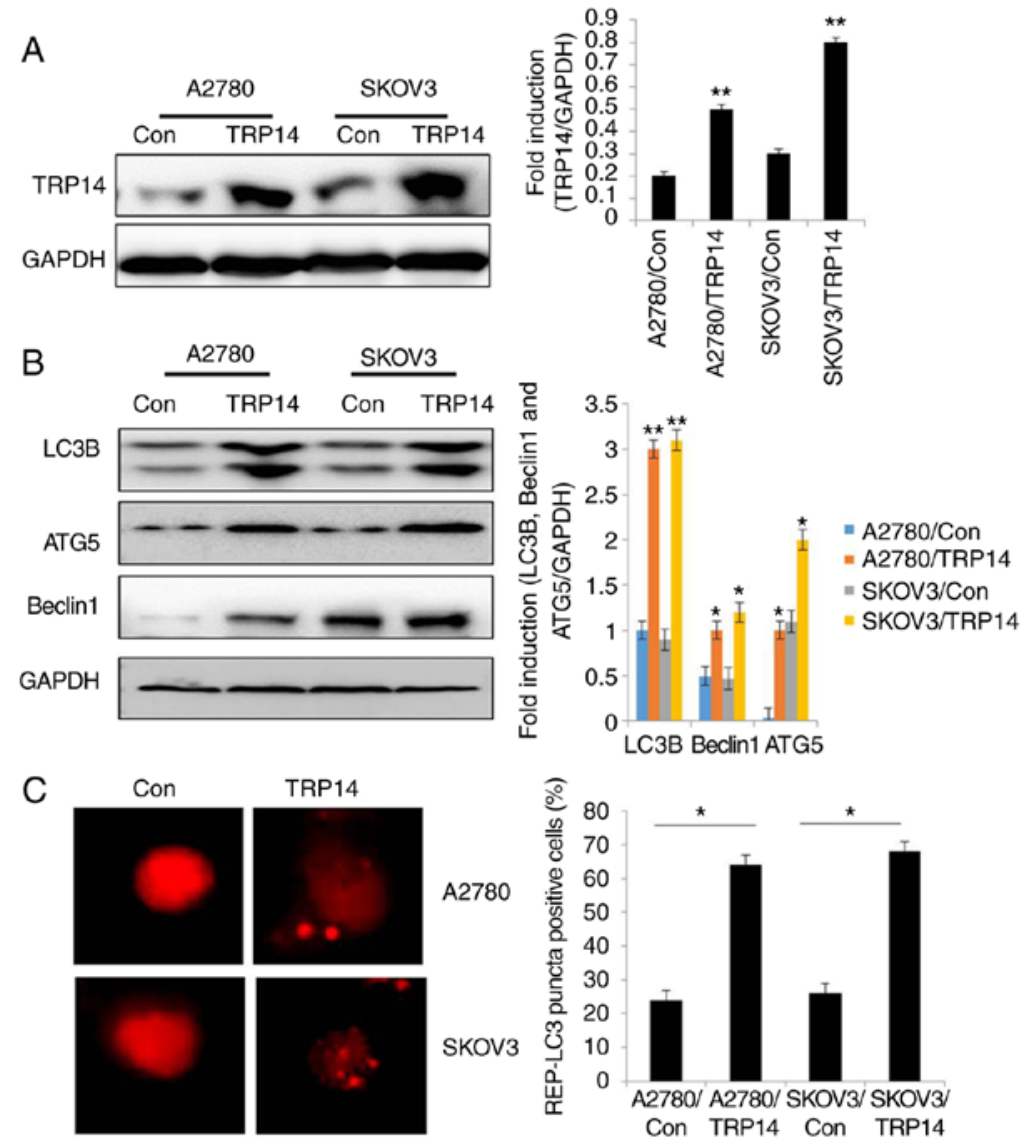

SKOV3
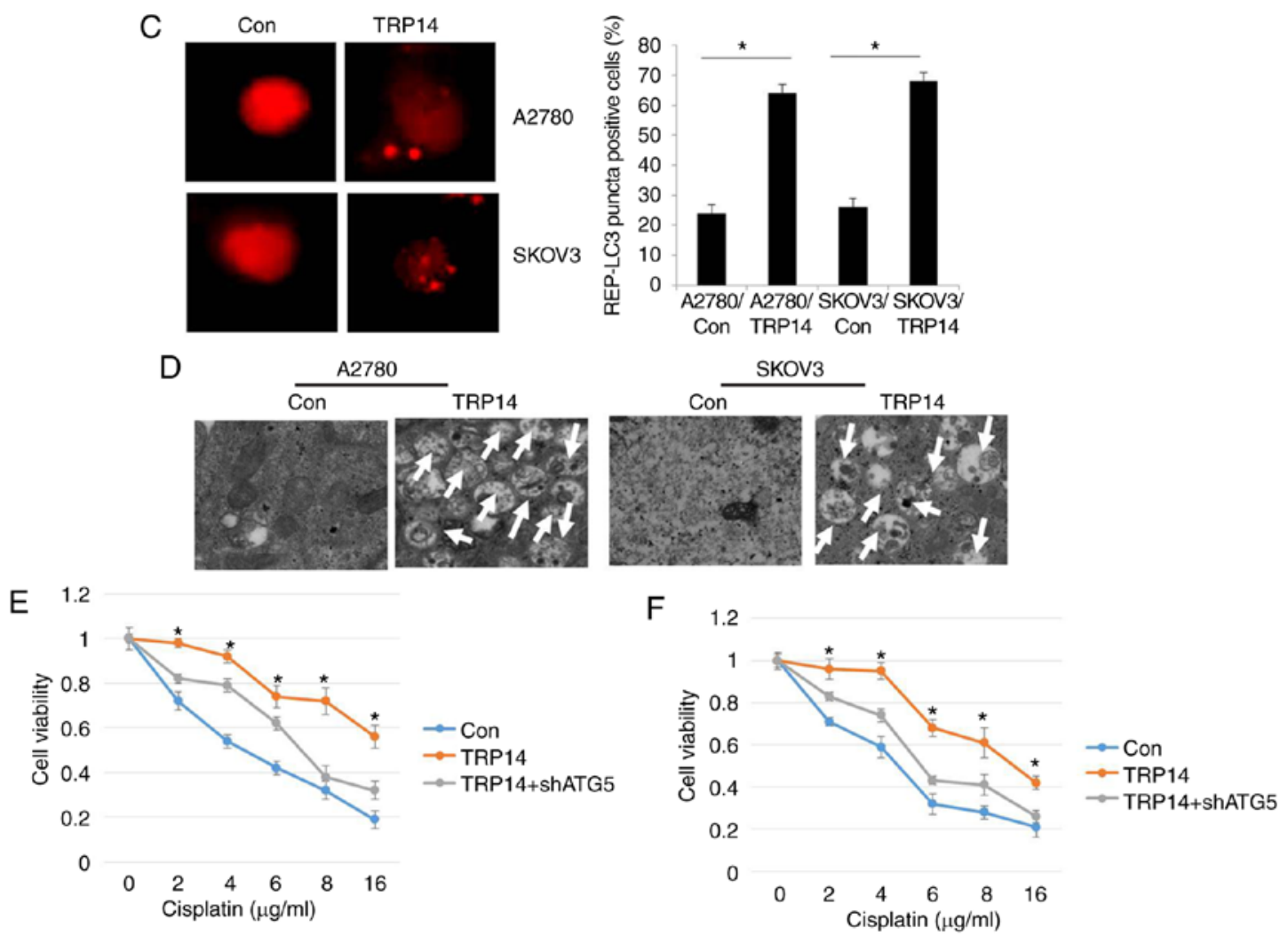

Figure 4. TRP14 overexpression promotes autophagy and cisplatin resistance in human ovarian cancer cells. (A) The levels of TRP14 were detected by western blot analysis in A2780 and SKOV3 cells by the overexpression of TRP14. ${ }^{* *} \mathrm{P}<0.01$ indicates statistical significance vs. control cells. (B) Autophagy-associated genes (LC3, Beclin1 and ATG5) were examined in A2780 and SKOV3 cells following TRP14 overexpression. "P<0.05 and ${ }^{* *} \mathrm{P}<0.01$, statistical significance vs. control cells. (C) Overexpression of TRP14 in A2780 and SKOV3 cells and then cells were transfected with GFP-RFP-LC3-plasmid overnight. Representative images of GFP- RFP-LC3-II-positive puncta were obtained using a confocal fluorescence microscope. " $\mathrm{P}<0.05$, statistical significance vs. control cells. (D) Autophagosome and autolysosome vesicles of A2780 and SKOV3 cells following the overexpression of TRP14 were visualized by transmission electron microscopy. The white arrows indicated typical images of autophagosomes and autolysosomes. (E) TRP14-overexpressing SKOV3/DDP cells were transfected with or without ATG5 shRNA. The cells were then treated with the indicated concentrations of cisplatin (from o to $16 \mu \mathrm{g} / \mathrm{ml}$ ) for $24 \mathrm{~h}$ and cell viability was measured by CCK- 8 assay. The Kruskal-Wallis was used for multiple comparisons and then Mann Whitney U test and Bonferroni's correction were applied. The values are presented as the means $\pm \operatorname{SEM}(\mathrm{n}=3)$. ${ }^{*} \mathrm{P}<0.05$, statistical significance vs. TRP14-overexpressing cells. (F) TRP14-overexpressing A2780 cells were transfected with or without ATG5 shRNA. The cells were then treated with the indicated concentrations of cisplatin (from o to $16 \mu \mathrm{g} / \mathrm{ml}$ ) for $24 \mathrm{~h}$ and cell viability was measured by CCK-8 assay. The Kruskal-Wallis was used for multiple comparisons and then Mann Whitney U test and Bonferroni's correction were applied. The values are presented as the means \pm SEM $(n=3)$. " $P<0.05$, statistical significance vs. TRP14-overexpressing cells.

TRP14 induces autophagy and chemoresistence via the AMPK/mTOR/p70S6K signaling pathway. Subsequenlty, the AMPK and mTOR signaling pathways were investigated in the cisplatin-resistant human ovarian cancer cells. According to a previous study, the AMPK and MTOR signaling pathways regulate autophagy (30). Western blot analysis was thus 

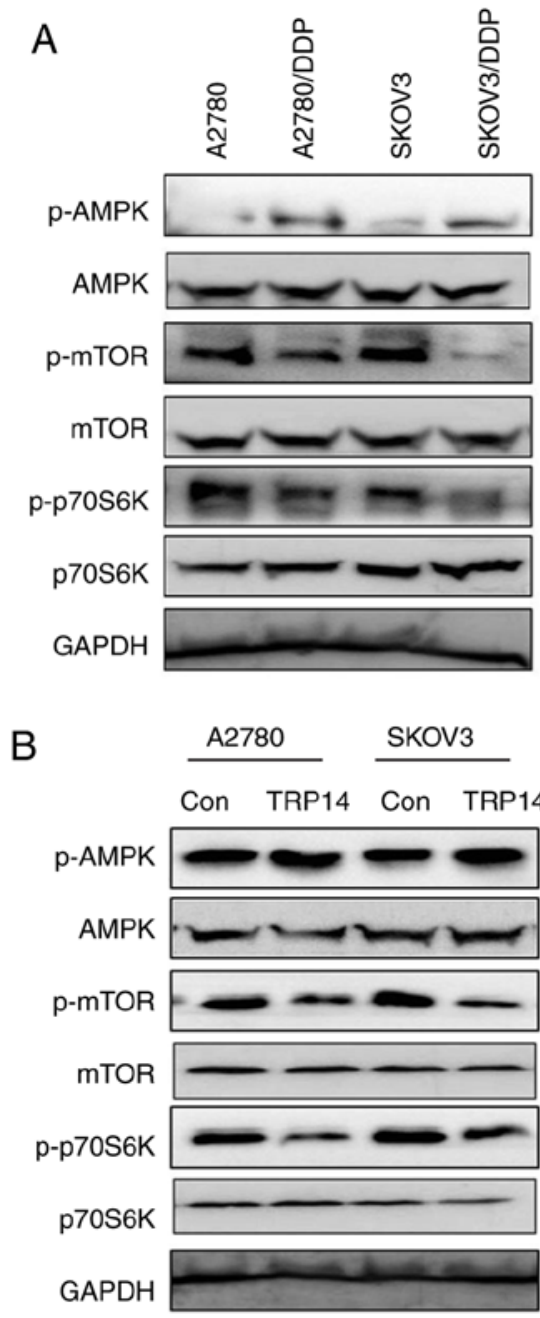
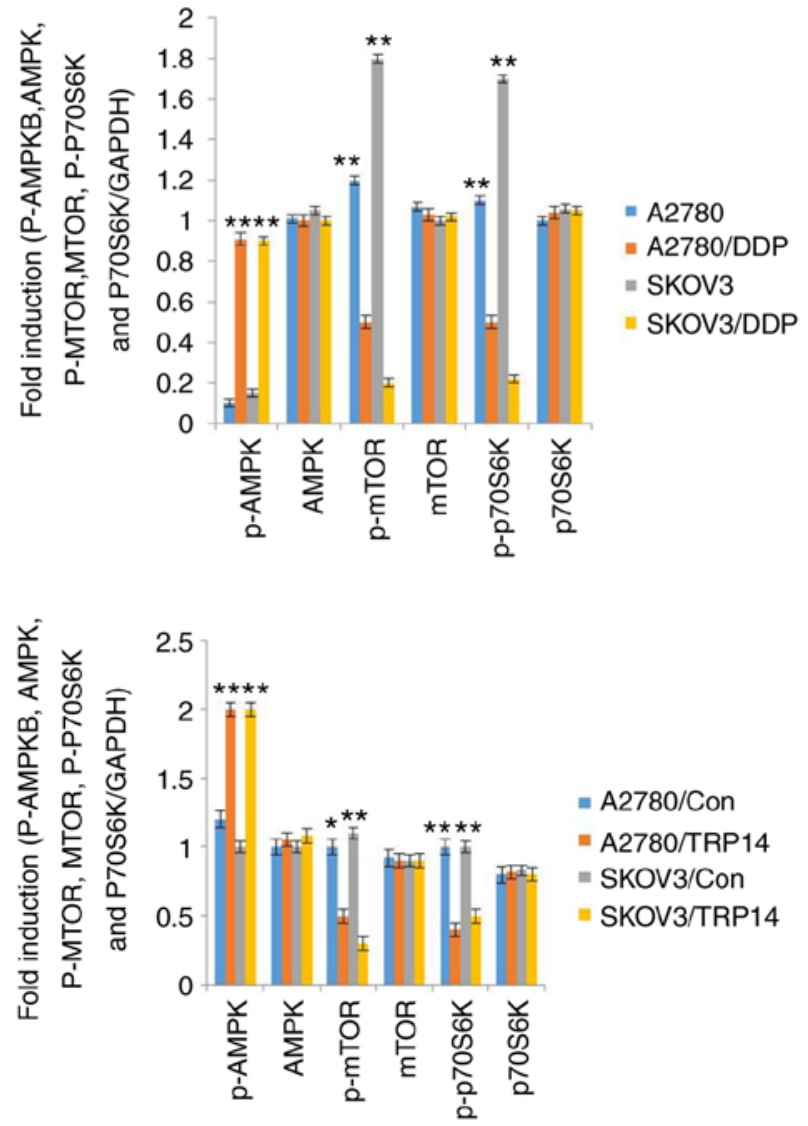
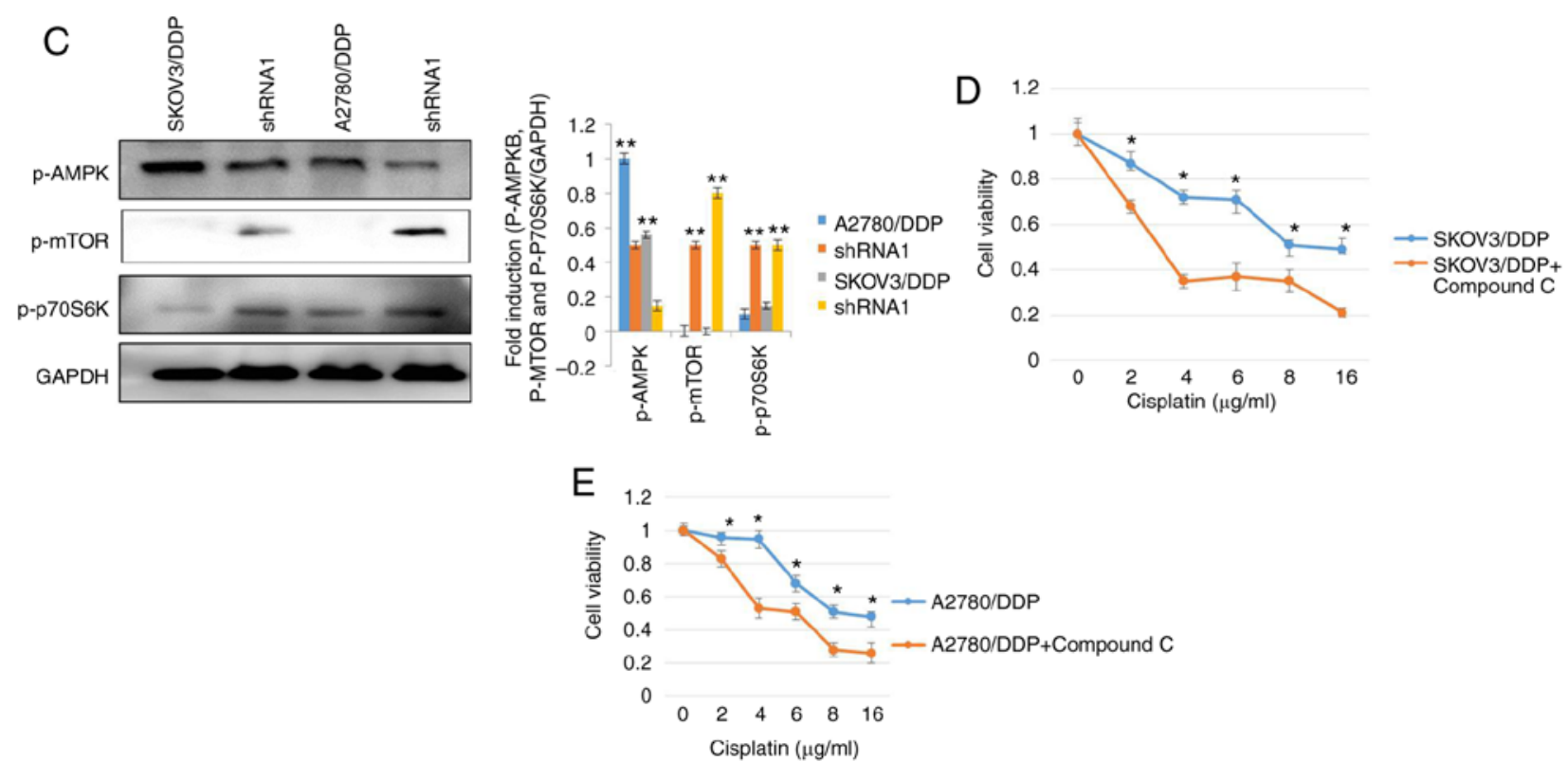

Figure 5. TRP14 induces autophagy and chemoresistence via the AMPK/mTOR/p70S6K signaling pathway. (A) The phosphorylation levels of AMPK, mTOR and p70S6K were detected by western blot analysis in A2780/DDP and SKOV3/DDP cells. ${ }^{* *} \mathrm{P}<0.01$, statistical significance vs. normal A2780 and SKOV3 cells. (B) The phosphorylation levels of p-AMPK, p-mTOR and p70S6K were detected by western blot analysis in SKOV3 and A2780 cells following the overexpression of TRP14. ${ }^{*} \mathrm{P}<0.05$ and ${ }^{* *} \mathrm{P}<0.01$, statistical significance vs. normal A2780 and SKOV3 cells. (C) The phosphorylation levels of p-AMPK, p-mTOR and p70S6K were detected by western blot analysis in A2780/DDP and SKOV3/DDP cells following TRP14 knockdown. ${ }^{* *} \mathrm{P}<0.01$, statistical significance vs. TRP14-knockdown cells. (D) SKOV3/DDP cells were treated with $4 \mu \mathrm{M}$ compound C for $12 \mathrm{~h}$. The cells were then treated with the indicated concentrations of cisplatin and cell viability was measured by CCK- 8 assay. Values are presented as the means $\pm \mathrm{SEM}(\mathrm{n}=3)$. ${ }^{*} \mathrm{P}<0.05$, statistical significance vs. compound C-treated cells. (E) A2780/DDP cells were treated with $4 \mu \mathrm{M}$ compound $\mathrm{C}$ for $12 \mathrm{~h}$. The cells were then treated with the indicated concentrations of cisplatin and cell viability was measured by CCK- 8 assay. Values are presented as the means $\pm \operatorname{SEM}(n=3)$. $P<0.05$, statistical significance vs. compound $C$-treated cells. 
A

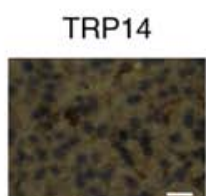

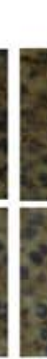

Cancer
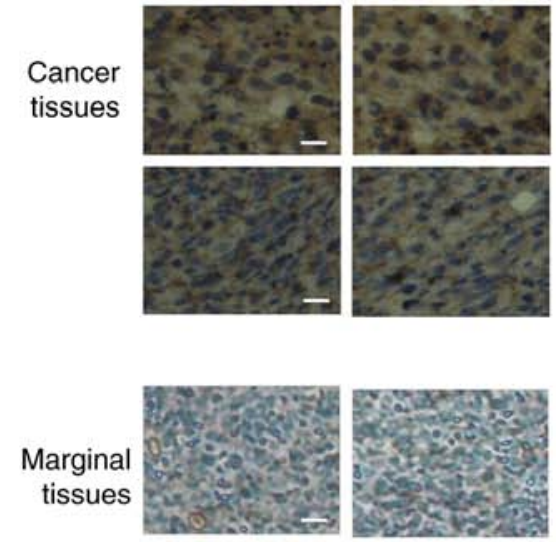

B

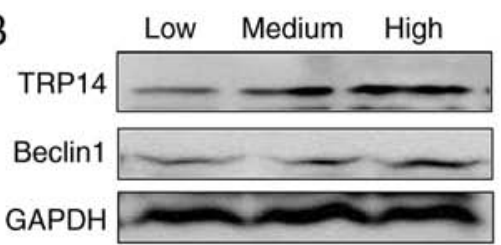

High
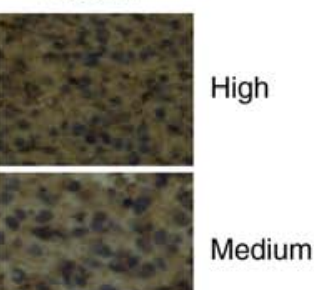

Medium

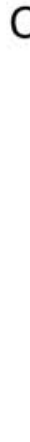

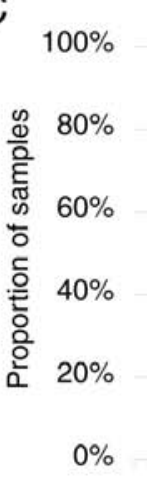

Figure 6. The positive association of TRP14 and Beclin 1 proteins in ovarian tissues. (A) Human ovarian cancer and marginal tissue specimens (BC11115b) were subjected to immunohistochemistry (IHC) using antibodies against TRP14 and Beclin1. Representative stains from the samples are shown. Scale bar, $100 \mu \mathrm{m}$. (B) The levels of TRP14 and Beclin1 were detected by western blot analysis in ovarian cancer tissues. ${ }^{*} \mathrm{P}<0.05$ and ${ }^{* *} \mathrm{P}<0.01$, statistical significance vs. low TRP14 expression group. (C) The association between the TRP14 and Beclin1 level was analyzed by the Kruskal-Wallis test. ${ }^{*} \mathrm{P}<0.05$, statistical significance.

performed to elucidate the phosphorylation levels of AMPK, mTOR and p70S6K in the SKOV3/DDP and A2780/DDP cells. As shown in Fig. 5A, the phosphorylation levels of AMPK were increased in the SKOV3/DDP and A2780/DDP cells, whereas the phosphorylation levels of mTOR and p70S6K were decreased. These results indicated the involvement of autophagy in cisplatin-resistant human ovarian cancer cells and the role of the AMPK/mTOR/p70S6K signaling pathway. To further confirm the involvement of AMPK, mTOR and p70S6K signaling in cisplatin-resistant human ovarian cancer cells and the induction of autophagy, the AMPK inhibitor, compound C, was employed. Compound C partially, but significantly reversed cisplatin-resistance in the SKOV3/DDP and A2780/DDP cells (Fig. 5D and E). These results clearly indicated that cisplatin resistance was mediated by AMPK, mTOR and p70S6K signaling in ovarian cancer cells. Our results also revealed that TRP14 acts as an autophagy and chemoresistence promoter (Figs. 3 and 4). Thus, we investigated the association of the TRP14 in the AMPK/mTOR/p70S6K signaling pathway. TRP14 was overexpressed in the SKOV3 and A2780 cells and detected the phosphorylation levels of AMPK, mTOR and p70S6K. These results suggested that TRP14 markedly activated the AMPK/mTOR/p70S6K signaling pathway (Fig. 5B). To further validate the regulation of the AMPK/mTOR/p70S6K signaling pathway by TRP14, TRP14 shRNA2 was used in SKOV3/DDP and A2780/DDP cells. As expected, the phosphorylation of AMPK exhibited a decrease, whereas the phosphorylation of mTOR and p70S6K exhibited an increase (Fig. 5C). These findings revealed that TRP14 induced autophagy and chemoresistence via the AMPK/mTOR/p70S6K signaling pathway.
Positive association of TRP14 and Beclinl proteins in ovarian cancer tissues. The above-mentioned results supported the conclusion that TRP14 promotes paclitaxel resistance by inducing autophagy via the AMPK/mTOR/p70S6K signaling pathway in ovarian cancer. To further determine whether there was an association between TRP14 and Beclin1, we used a tissue array of human ovarian cancer. The tissue array was composed of 5 cases of clear cell carcinoma, 62 cases of serous adenocarcinoma, 12 cases of mucinous adenocarcinoma, 1 case of endometrioid carcinoma, 10 cases of lymph node metastatic adenocarcinoma and 10 cases of marginal tissue. The representative strains from the specimens are shown in Fig. 6A and B. The results revealed that along with the increment in the TRP14 protein levels, the expression of Beclin1 was markedly increased (Fig. 6C). Collectively, these results strongly suggested that the expression of TRP14 and Beclin1 proteins are positively associated in ovarian cancer tissues.

\section{Discussion}

Cisplatin is known as the 'penicillin of cancer', and is widely used in the treatment of various types of cancer, including ovarian cancer. However, cisplatin-based resistance is a major obstacle in chemotherapy (31). The mechanisms associated with cisplatin resistance in ovarian cancer remain unclear. Hence, in this study, we aimed to elucidate the possible underlying mechanisms of the effects of cisplatin on ovarian cancer cells using sensitive SKOV3 (A2780) and resistant SKOV3/DDP (A2780/DDP) cells as the ideal pairs of cell models. 
Autophagy plays a dual role in cancer. According to some early reports, autophagy was considered to be a tumor suppressor (32), while others consider that cancer cells rely on autophagy (33). More importantly, there is increasing evidence to indicate that the activation of autophagy is involved in the chemoresistance of cancer cells, while the inhibition of autophagy significantly improves the effects of therapy (34-36). In this study, the levels of LC3, Beclin1 and ATG5 were compared in both ovarian cancer cells. Accordingly, the protein expression levels of LC3, Beclin1 and ATG5 were high in the cisplatin-resistant cells, while they were low in the sensitive cells (Fig. 1C). Consistent with these results, MDC staining, GFP-RFP-LC3 transfection and transmission electron microscopy analysis confirmed that cisplatin-resistant ovarian cancer cells triggered autophagy (Fig. 1). In line with previous findings (15), this study revealed that the inhibition of autophagy by treatment with 3-MA or the silencing of ATG5 augmented cisplatin cytotoxicity (Fig. 2), suggesting the importance of autophagy in the pharmacological modulation of ovarian cancer cells in response to cisplatin. Moreover, the induction of autophagy by Rapa increased the survival of the SKOV3 and A2780 cells (Fig. 2E-I). These data indicated that autophagic cell death was a possible mechanism for cisplatin-induced cytotoxicity and changes in autophagy in the sensitivity to chemotherapy.

There is increasing evidence to indicate that TRP14 promotes taxol resistance by inducing autophagy (25). To confirm whether TRP14 also participates in autophagy-mediated cisplatin resistance in ovarian cancer cells, the expression of TRP14 was initially detected. The protein levels of TRP14 were substantially increased in SKOV3/DDP and A2780/DDP cells (Fig. 3A). To illustrate the role of TRP14 in the resistance of ovarian cancer, TRP14 was knocked down using shRNA (Fig. 3B). The results revealed that cisplatin sensitivity was increased when TRP14 was substantially suppressed by shRNA (Fig. 3D-H). By contrast, autophagy was induced and cisplatin sensitivity was attenuated when TRP14 was overexpressed (Fig. 4). Taken together, these results clearly demonstrated that TRP14 induced cisplatin resistance, at least partly by inducing autophagy.

Based on the clinical data of the connection between autophagy and the AMPK/mTOR signaling pathway, the signaling pathway in resistant human ovarian cancer cells was evaluated. As shown in Fig. 5, the overexpression of TRP14 in the SKOV3 and A2780 cells activated the AMPK signal, and inhibited the mTOR and p70S6K signaling pathways. Based on these data, TRP14 may modulate these molecules, and it may be located upstream of these molecules. Moreover, the data from a tissue array (Fig. 6) suggested that the protein expression of TRP14 and Beclin1 exhibited a positive association, supporting the view that TRP14 activated autophagy in ovarian cancer cells.

In conclusion, this study, identified that TRP14 mediated cisplatin resistance through the induction of autophagy in human ovarian cancer cells via the AMPK/mTOR/p70S6K signaling pathway. Moreover, TRP14 and Beclin1 were positively associated in human ovarian cancer and marginal tissues. Although the detailed underlying mechanisms require further investigation, TRP14 may be regarded as a promising therapeutic target for managing cisplatin resistance in human ovarian cancer.

\section{Acknowledgements}

Not applicable.

\section{Funding}

This study was supported by grants from the National Natural Science Foundation of China (nos. 81772772 and 81302242).

\section{Availability of data and materials}

All data generated or analyzed during this study are included in this published article or are available from the corresponding author on reasonable request.

\section{Authors' contributions}

MHC, WXT and TMX conceived and designed the experiments. WXT, XJL and ZLZ performed the experiments. JL and WJZ performed data analysis. ZLZ, XJL, JL and WJZ contributed the provision of the reagents/materials/analysis tools. MHC and TMX contributed intellectually to the interpretation and discussion of the results. WXT contributed to the writing of the manuscript. All authors have read and approved the final manuscript.

\section{Ethics approval and consent to participate}

The tissue samples used in this study were from a tissue microarray; thus, ethics approval does not apply.

\section{Patient consent for publication}

Not applicable.

\section{Competing interests}

The authors declare that they have no competing interest.

\section{References}

1. Cho YJ, Woo JH, Lee JS, Jang DS, Lee KT and Choi JH: Eclalbasaponin II induces autophagic and apoptotic cell death in human ovarian cancer cells. J Pharmacol Sci 132: 6-14, 2016.

2. Liang B, Liu X, Liu Y, Kong D, Liu X, Zhong R and Ma S: Inhibition of autophagy sensitizes MDR-phenotype ovarian cancer SKVCR cells to chemotherapy. Biomed Pharmacother 82: 98-105, 2016.

3. Siegel R, Naishadham D and Jemal A: Cancer statistics, 2012. CA Cancer J Clin 62: 10-29, 2012.

4. Gossner G, Choi M, Tan L, Fogoros S, Griffith KA, Kuenker M and Liu JR: Genistein-induced apoptosis and autophagocytosis in ovarian cancer cells. Gynecol Oncol 105: 23-30, 2007.

5. Ozols RF: Treatment goals in ovarian cancer. Int J Gynecol Cancer 15: 3-11, 2005.

6. Piccart MJ, Lamb H and Vermorken JB: Current and future potential roles of the platinum drugs in the treatment of ovarian cancer. Ann Oncol 12: 1195-1203, 2001.

7. Strzyz P: Autophagy: Mitochondria encaged. Nat Rev Mol Cell Biol 19: 212, 2018.

8. Guan Y, Li YP, Zhao G and Li YQ: HMGB1 promotes the starvation-induced autophagic degradation of alpha-synuclein in SH-SY5Y cells Atg 5-dependently. Life Sci 202: 1-10, 2018. 
9. Fritzen AM, Frosig C, Jeppesen J, Jensen TE, Lundsgaard AM, Serup AK, Schjerling P, Proud CG, Richter EA and Kiens B: Role of AMPK in regulation of LC3 lipidation as a marker of autophagy in skeletal muscle. Cell Signal 28: 663-674, 2016.

10. Chen GH, Liu HC, Zhang YD, Liang J, Zhu Y, Zhang M, Yu D, Wang $\mathrm{C}$ and Hou J: Silencing PFKP inhibits starvation-induced autophagy, glycolysis, and epithelial mesenchymal transition in oral squamous cell carcinoma. Exp Cell Res 370: 46-57, 2018.

11. Klionsky DJ, Abdalla FC, Abeliovich H, Abraham RT, Acevedo-Arozena A, Adeli K, Agholme L, Agnello M, Agostinis P, Aguirre-Ghiso JA, et al: Guidelines for the use and interpretation of assays for monitoring autophagy. Autophagy 8: 445-544, 2012.

12. Paglin S, Hollister T, Delohery T, Hackett N, McMahill M, Sphicas E, Domingo D and Yahalom J: A novel response of cancer cells to radiation involves autophagy and formation of acidic vesicles. Cancer Res 61: 439-444, 2001.

13. Wang Y, Gan G, Wang B, Wu J, Cao Y, Zhu D, Xu Y, Wang X, Han H, Li X, et al: Cancer-associated fibroblasts promote irradiated cancer cell recovery through autophagy. EbioMedicine 17: 45-56, 2017.

14. Kondo Y, Kanzawa T, Sawaya R and Kondo S: The role of autophagy in cancer development and response to therapy. Nat Rev Cancer 5: 726-734, 2005.

15. Leng SL, Hao YL, Du DB, Xie S, Hong L, Gu H, Zhu X, Zhang J, Fan D and Kung HF: Ursolic acid promotes cancer cell death by inducing Atg5-dependent autophagy. Int J Cancer 133: 2781-2790, 2013

16. Wu BW, Tan MD, Cai WL, Wang B, He PH and Zhang XP: Arsenic trioxide induces autophagic cell death in osteosarcoma cells via the ROS-TFEB signaling pathway. Biochem Bioph Res Commun 496: 167-175, 2018.

17. Wang XY, Wei SH, Zhao Y, Shi C, Liu P, Zhang C, Lei Y, Zhang B, Bai B, Huang $\mathrm{Y}$ and Zhang H: Anti-proliferation of breast cancer cells with itraconazole: Hedgehog pathway inhibition induces apoptosis and autophagic cell death. Cancer Lett 385: 128-136, 2017.

18. Chen Z, Teo AE and McCarty N: ROS-induced CXCR4 signaling regulates mantle cell lymphoma (MCL) cell survival and drug resistance in the bone marrow microenvironment via autophagy. Clin Cancer Res 22: 187-199, 2016.

19. Kumar A, Singh UK and Chaudhary A: Targeting autophagy to overcome drug resistance in cancer therapy. Future Med Chem 7: $1535-1542,2015$

20. Zhao J, Nie YQ, Wang H and Lin Y: MiR-181a suppresses autophagy and sensitizes gastric cancer cells to cisplatin. Gene 576: 828-833, 2016.

21. DeVorkin L, Hattersley M, Kim P, Ries J, Spowart J, Anglesio MS, Levi SM, Huntsman DG, Amaravadi RK, Winkler JD, et al: Autophagy inhibition enhances sunitinib efficacy in clear cell ovarian carcinoma. Mol Cancer Res 15: 250-258, 2017.

22. Zhang ZD, Wang AH, Li H, Zhi H and Lu F: STAT3-dependent TXNDC17 expression mediates taxol resistance through inducing autophagy in human colorectal cancer cells. Gene 584: 75-82, 2016.

23. Jeong W, Yoon HW, Lee SR and Rhee SG: Identification and characterization of TRP14, a thioredoxin-related protein of $14 \mathrm{kDa}-$ new insights into the specificity of thioredoxin function. J Biol Chem 279: 3142-3150, 2004.
24. Pader I, Sengupta R, Cebula M, Xu J, Lundberg JO, Holmgren A, Johansson $\mathrm{K}$ and Arnér ES: Thioredoxin-related protein of $14 \mathrm{kDa}$ is an efficient L-cystine reductase and S-denitrosylase. Proc Natl Acad Sci USA 111: 6964-6969, 2014.

25. Zhang SF, Wang XY, Fu ZQ, Peng QH, Zhang JY, Ye F, Fu YF, Zhou CY, Lu WG, Cheng XD and Xie X: TXNDC17 promotes paclitaxel resistance via inducing autophagy in ovarian cancer. Autophagy 11: 225-238, 2015.

26. Song ZB, Ni JS, Wu P, Bao YL, Liu T, Li M, Fan C, Zhang WJ, Sun LG, Huang YX and Li YX: Testes-specific protease 50 promotes cell invasion and metastasis by increasing NF-kappaB-dependent matrix metalloproteinase-9 expression. Cell Death Dis 26: e1703, 2015.

27. Zhang WJ, Song ZB, Bao YL, Li WL, Yang XG, Wang Q, Yu CL, Sun LG, Huang YX and Li YX: Periplogenin induces necroptotic cell death through oxidative stress in $\mathrm{HaCaT}$ cells and ameliorates skin lesions in the TPA- and IMQ-induced psoriasis-like mouse models. Biochem Pharmacol 105: 66-79, 2016.

28. Peng X, Gong F, Chen Y, Jiang Y, Liu J, Yu M, Zhang S, Wang M, Xiao G and Liao H: Autophagy promotes paclitaxel resistance of cervical cancer cells: Involvement of warburg effect activated hypoxia-induced factor 1- $\alpha$-mediated signaling. Cell Death Dis 14: e1367, 2014

29. Shin D, Kim EH, Lee J and Roh JL: RITA plus 3-MA overcomes chemoresistance of head and neck cancer cells via dual inhibition of autophagy and antioxidant systems. Redox Biol 13: 219-227, 2017.

30. Yang Y, Gao JF, Zhang Y, Xu W, Hao Y, Xu Z and Tao L: Natural pyrethrins induce autophagy of HepG2 cells through the activation of AMPK/mTOR pathway. Environ Pollut 241: 1091-1097, 2018.

31. Bao LJ, Jaramillo MC, Zhang ZB, Zheng YX, Yao M, Zhang DD and Yi XF: Nrf2 induces cisplatin resistance through activation of autophagy in ovarian carcinoma. Int J Clin Exp Pathol 7: 1502-1513, 2014

32. Laddha SV, Ganesan S, Chan CS and White E: Mutational landscape of the essential autophagy gene BECN1 in human cancers. Mol Cancer Res 12: 485-490, 2014.

33. Kuo YZ, Tai YH, Lo HI, Chen YL, Cheng HC, Fang WY, Lin SH, Yang CL, Tsai ST and Wu LW: MiR-99a exerts anti-metastasis through inhibiting myotubularin-related protein 3 expression in oral cancer. Oral Dis 20: e65-e75, 2014.

34. Qiao SX, Tao SS, de la Vega MR, Park SL, Vonderfecht AA, Jacobs SL, Zhang DD and Wondrak GT: The antimalarial amodiaquine causes autophagic-lysosomal and proliferative blockade sensitizing human melanoma cells to starvation- and chemotherapy-induced cell death. Autophagy 9: 2087-2102, 2013.

35. Ajabnoor GMA, Crook T and Coley HM: Paclitaxel resistance is associated with switch from apoptotic to autophagic cell death in MCF-7 breast cancer cells. Cell Death Dis 26: e260, 2012.

36. Yin X, Zhang N and Di W: Regulation of LC3-dependent protective autophagy in ovarian cancer cells by protein phosphatase 2A. Int J Gynecol Cancer 23: 630-641, 2013.

This work is licensed under a Creative Commons Attribution-NonCommercial-NoDerivatives 4.0 International (CC BY-NC-ND 4.0) License. 